\title{
PORT-ACCESS MITRAL VALVE REPLACEMENT IN DOGS
}

Mario F. Pompili, MD

John H. Stevens, MD

Thoms A. Burdon MD

Lawrence C. Siegel, MD

William S. Peters, MB, ChB

Greg H. Ribakove, MD

Bruce A. Reitz, MD
Objective: The objective was to assess mitral valve replacement in a minimally invasive fashion by means of port-access technology. Methods: Fifteen dogs, $28 \pm 3$ $\mathrm{kg}$ (mean \pm standard deviation), were studied with the port-access mitral valve replacement system (Heartport, Inc., Redwood City, Calif.). Eleven dogs underwent acute studies and were sacrificed immediately after the procedure. Four dogs were allowed to recover and then were sacrificed 4 weeks after operation. Cardiopulmonary bypass was conducted by femoral cannulation with an endovascular balloon catheter for aortic occlusion, root venting, and antegrade delivery of cardioplegic solution. Catheters were inserted in the jugular vein for pulmonary artery venting and retrograde delivery of cardioplegic solution. Through the oval port, a prosthesis (St. Jude Medical, Inc., St. Paul, Minn., or CarboMedics, Inc., Austin, Texas) was inserted through the left atrial appendage and secured to the anulus with sutures. Deairing was performed. Results: Cardiopulmonary bypass duration was $114 \pm 24$ minutes and aortic crossclamp time was $68 \pm 14$ minutes. All animals were weaned from cardiopulmonary bypass in sinus rhythm. Cardiac output and pulmonary artery occlusion pressure were unchanged $(2.8 \pm 0.7 \mathrm{~L} / \mathrm{min}$ and $7 \pm 3 \mathrm{~mm} \mathrm{Hg}$ before operation vs $2.6 \pm 0.6 \mathrm{~L} / \mathrm{min}$ and $9 \pm 4 \mathrm{~mm} \mathrm{Hg}$ after operation). There was no mitral regurgitation according to left ventriculography in 13 of 15 dogs. In two dogs there was interference with prosthetic valve closure by residual native anterior leaflet tissue. Pathologic examination otherwise showed normal healing without perivalvular discontinuity. Microscopic studies showed no damage to the valve surfaces. Transthoracic echocardiography of the four dogs in the long-term study showed normal ventricular and prosthetic valve function 4 weeks after the operation. Conclusion: Mitral valve replacement with a minimally invasive method has been demonstrated in dogs. A clinical trial is in progress. (J Thorac Cardiovasc Surg 1996;112:1268-74)
$D^{\prime}$ uring the last few years, there has been significant development in the area of video-assisted surgical procedures. ${ }^{1}$ Important advances have been achieved in the diagnosis and treatment of diseases of the chest in a minimally invasive

From the Departments of Cardiothoracic Surgery and Anesthesia, Stanford University School of Medicine, Stanford, Calif., and the Division of Cardiothoracic Surgery, Veterans Affairs Palo Alto Health Care System, Palo Alto, Calif.

Supported by a grant from Heartport, Inc., Redwood City, Calif.

Read at the Seventy-sixth Annual Meeting of the American Association for Thoracic Surgery, San Diego, Calif., April 28-May 1, 1996.

Received for publication April 30, 1996; revisions requested June 6, 1996; revisions received June 19, 1996; accepted for publication July 24, 1996.

Reprint requests: Mario F. Pompili, MD, Division of Cardiothoracic Surgery Palo Alto Veterans Affairs HCS 3801 Miranda Avenue Palo Alto, CA 94305.

$12 / 6 / 76823$ fashion. $^{2}$ The application of this technique to cardiac surgical procedures, however, has been rather slow. The inability to provide cardiopulmonary support and myocardial protection without performing a median sternotomy or gross thoracotomy has represented a significant hurdle, limiting the implementation of such new technologies in cardiac surgery.

The surgical management of mitral valve disease has been well established since the early 1960 s. Replacement of the mitral valve with a mechanical prosthesis was first performed in 1960 by Starr and Edwards. ${ }^{3}$ Subsequent refinements and progress in the materials and design of valvular prosthesis have led to continuous improvement in the results of surgical therapy of mitral valve disease. ${ }^{4-6}$

On the basis of these preliminary considerations, we developed a procedure called "port-access mitral valve replacement." Our procedure allows establishment of full cardiopulmonary bypass (CPB), car- 


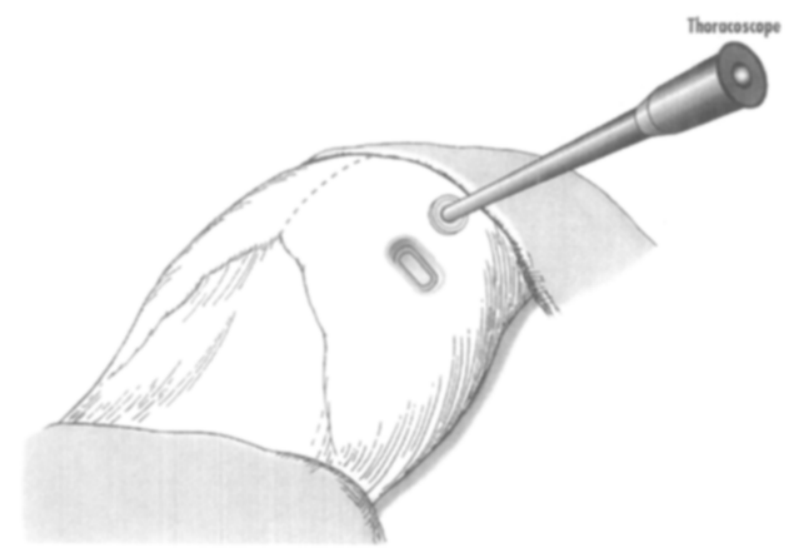

Fig. 1. Diagram of oval port and thoracoscope.

dioplegic arrest of the heart, and myocardial protection without gross opening of the chest. This study was aimed at evaluating in the canine model a minimally invasive system for replacement of the mitral valve.

\section{Methods}

The port-access mitral valve replacement procedure was performed in 15 dogs $(28 \pm 3 \mathrm{~kg}$, mean \pm standard deviation). Eleven dogs were studied during the acute phase and sacrificed after the study. Four dogs were allowed to recover and humanely killed after 4 weeks. The dog was selected for the experimental model because of the similarity of its cardiac anatomy to that of human beings.

All animals received humane care in accordance with the "Principles of Laboratory Animal Care" formulated by the National Society for Medical Research and the "Guide for the Care and Use of Laboratory Animals" prepared by the Institute of Laboratory Animal Resources and published by the National Institutes of Health (NIH publication No. 86-23, revised 1985).

Anesthesia was induced with $10 \mathrm{mg} / \mathrm{kg}$ tiletaminezolazepam (Telazol) and maintained with intravenous pentobarbital and inhaled isoflurane. All dogs were mechanically ventilated with $100 \%$ oxygen through an endotracheal tube. Single-lung ventilation was obtained with a bronchial blocker (Meditech; Boston Scientific Corp., Watertown, Mass.) placed in the left main bronchus with the aid of bronchoscopy.

The monitoring system consisted of a 7F thermodilution pulmonary artery catheter (Arrow International, Reading, $\mathrm{Pa}$.) placed through a $10 \mathrm{~F}$ venous sheath in the jugular vein. Baseline cardiac output (CO) and pulmonary artery occlusion pressure were measured. Central venous pressure was monitored off the side arm of the sheath. An arterial line was placed in the carotid artery, and electrocardiograms and rectal temperatures were also monitored.

All four long-term survival studies were performed under sterile techniques. All four dogs received intravenously a preoperative dose of $30 \mathrm{mg} / \mathrm{kg}$ cephalexin.

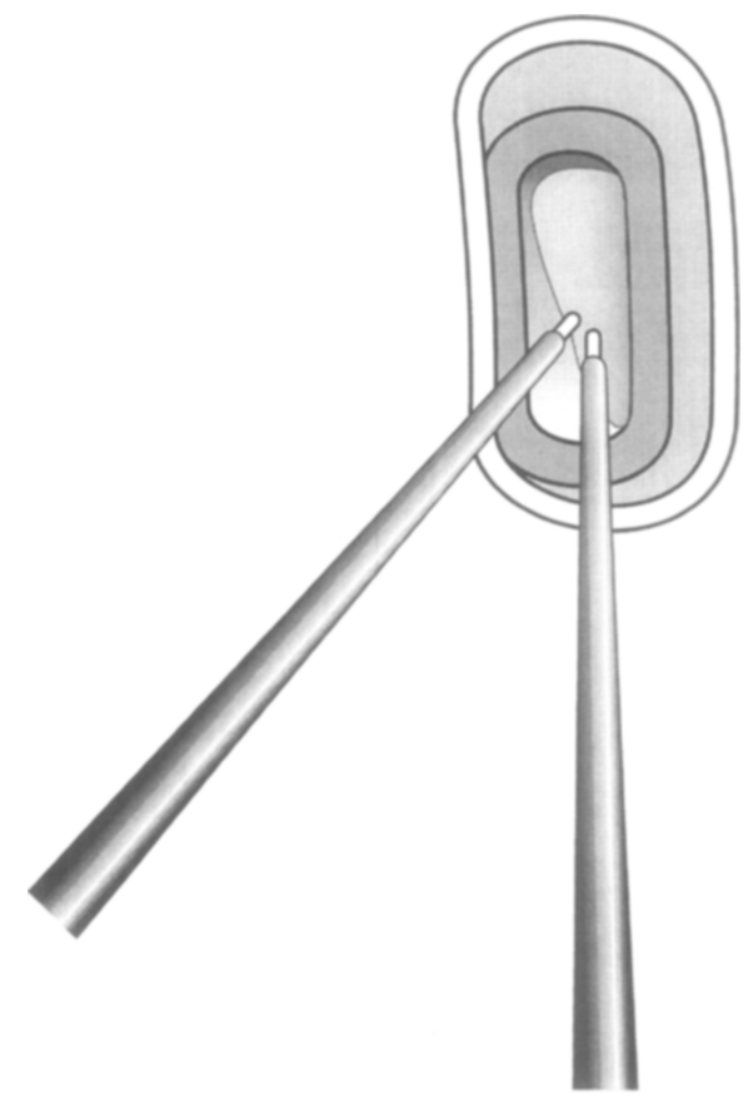

Fig. 2. Diagram of surgical instruments passed through oval port.

Access to the heart was gained through a $35 \times 17 \mathrm{~mm}$ oval port (Heartport, Inc., Redwood City, Calif.) placed in the fifth intercostal space between the midaxillary and posterior axillary lines. An additional $10 \mathrm{~mm}$ port was created in the fourth intercostal space for insertion of an articulating thoracoscope (Distalvu 360; Welch Allyn, Inc., Skaneateles Falls, N.Y.), as shown in Fig. 1. After deflation of the left lung, the pericardium was opened longitudinally anterior to the phrenic nerve with specifically designed instruments passed through the oval port (Fig. 2). During the surgical procedure, all the instruments were passed through the oval port. These specifically designed instruments are shown in Fig. 3. The atrial appendage was then suspended from the left anterior chest wall by means of temporary clips (Advanced Surgical, Inc., Princeton, N.J.). A myocardial temperature probe was also inserted in the left ventricular free wall (Mon-a-therm Myocardial; Mallinckrodt Medical, Inc., St. Louis, Mo; Fig. 4).

After systemic heparinization with $300 \mathrm{U} / \mathrm{kg}$ intravenous heparin, a $9.5 \mathrm{~F}$ endovascular pulmonary artery vent catheter (Endopulmonary Vent; Heartport) was inserted in place of the thermodilution pulmonary artery catheter and an $8.5 \mathrm{~F}$ coronary sinus cardioplegia catheter (Endosinus Catheter; Heartport) was positioned in the coronary sinus through a jugular vein under fluoroscopic guidance. 


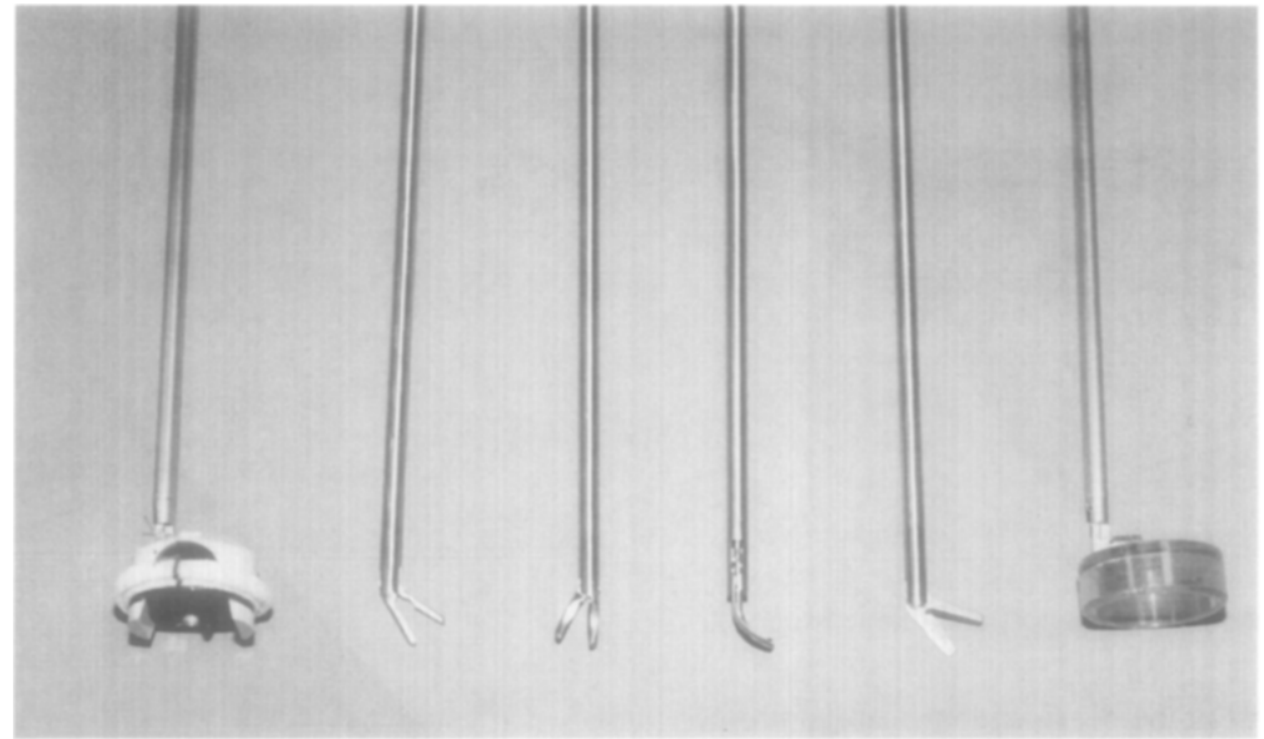

Fig. 3. Surgical instruments and valve with sizer.

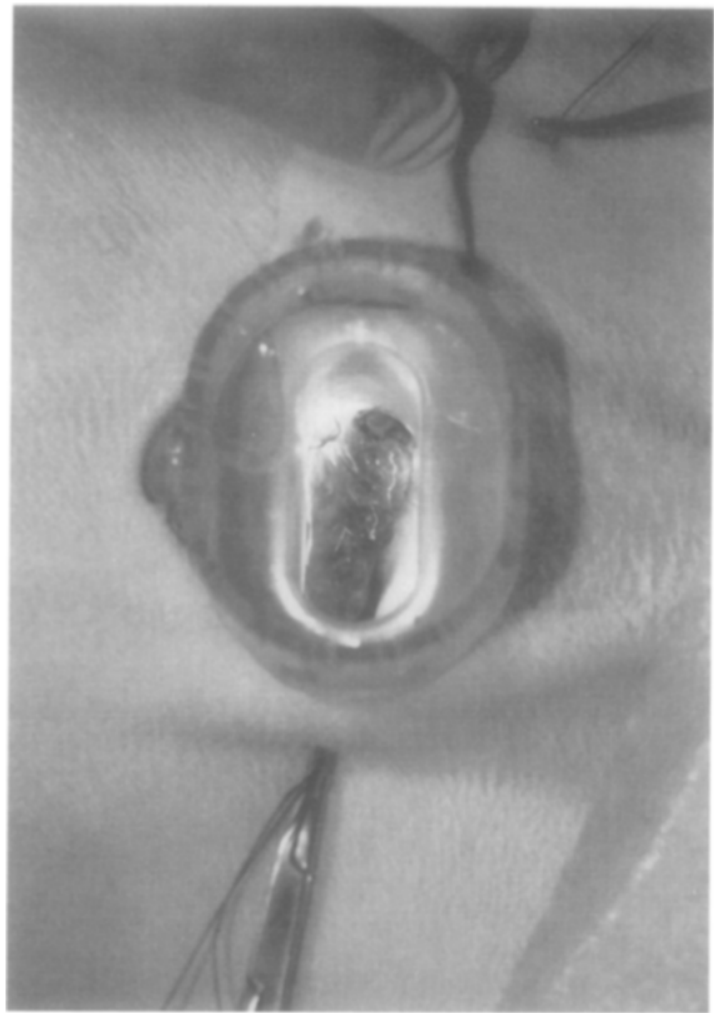

Fig. 4. Exposure of left atrial appendage through oval port.

The right femoral artery and vein, previously exposed, were cannulated with $14 \mathrm{~F}$ and $17 \mathrm{~F}$ cannulas, respectively (DLP, Inc., Grand Rapids, Mich.). The tip of the venous cannula was situated at the superior cavoatrial junction under fluoroscopic guidance. A $12 \mathrm{~F}$ endovascular threelumen balloon-tipped catheter (Endoaortic Clamp; Heartport) was introduced through the left femoral artery, and its tip was positioned in the ascending aorta under fluoroscopic guidance. The distal end of the endoaortic clamp was then connected to the balloon-inflation and aortic root pressure-monitoring lines, as well as to the cardioplegia and venting lines.

The arterial and venous lines were connected and CPB was instituted with systemic hypothermia between $20^{\circ}$ and $25^{\circ} \mathrm{C}$. A centrifugal pump with a remote driver (Sarns 8000; Sarns, 3M Health Care, Ann Arbor, Mich.) was used to augment venous drainage.

Under fluoroscopic guidance, the balloon was inflated and cold, high-potassium blood cardioplegic solution (20 $\mathrm{ml} / \mathrm{kg}$ ) was delivered in an antegrade fashion, maintaining an aortic root pressure between 50 and $70 \mathrm{~mm} \mathrm{Hg}$. After cardioplegic infusion and with the heart in diastolic arrest, the position of the Endovascular clamp was again checked fluoroscopically.

Cardioplegic solution was infused until a myocardial temperature of less than $15^{\circ} \mathrm{C}$ was achieved. Subsequently, it was infused at a dose of $10 \mathrm{ml} / \mathrm{kg}$ in a retrograde manner through the coronary sinus catheter (Endosinus Catheter; Heartport; Fig. 5) every 20 minutes or in the presence of any electrical activity.

The left atrial appendage was opened vertically, and with the aid of retraction suture the mitral valve was visualized directly and videothoracoscopically. The anulus was sized and sutures were inserted into it by means of specifically designed instruments. In all animals, the native valve was left in situ. The sutures were organized around the oval port (Fig. 6). These sutures were then passed through the sewing ring of the appropriately sized mitral valve prosthesis (St. Jude Medical, Inc., St. Paul, Minn.; or CarboMedics, Inc., Austin, Texas), which was then seated on the anulus of the mitral valve (Fig. 7). The sutures were 


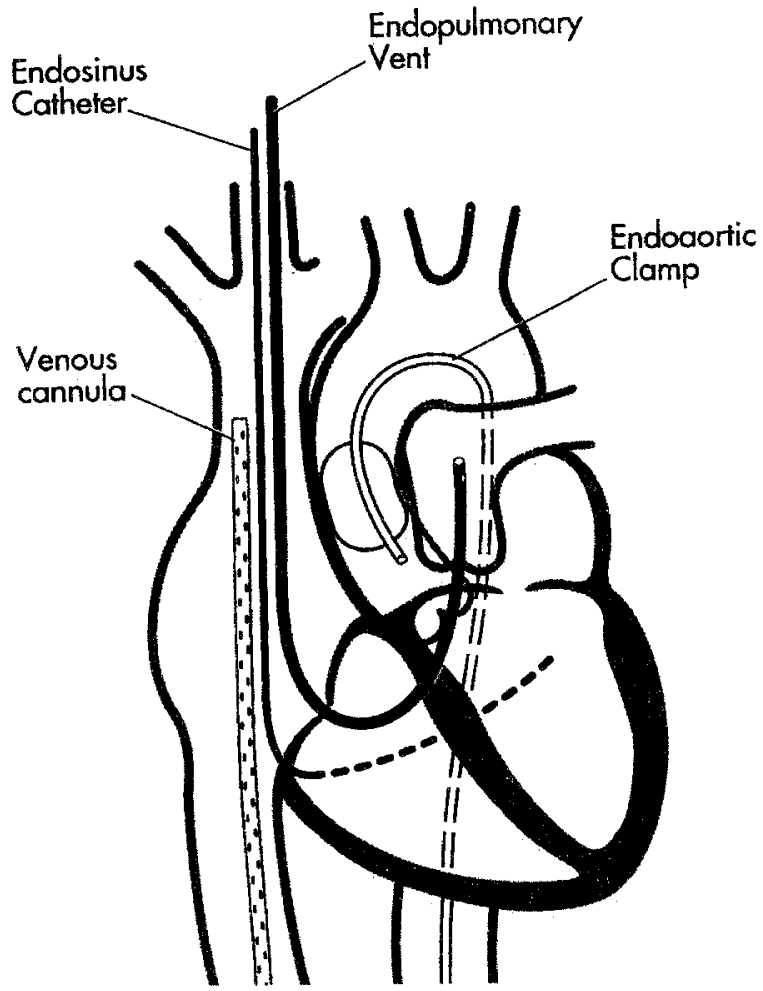

Fig. 5. Schematic diagram of endovascular CPB system.

tied, creating the knot outside the chest wall and sliding it with a knot pusher onto the sewing ring. The sutures were then cut and the valve leaflet motion was tested with a soft-tip probe (Fig. 8). Removal of any noncoronary collateral blood returning to the surgical field was accomplished with a cardiotomy aspirator passed through the oval port as necessary.

Rewarming was started while the atriotomy was being closed with 4-0 Prolene suture (Ethicon, Inc., Somerville, N.J.). Deairing was accomplished by turning off the pulmonary and aortic root venting lines, inflating the lungs to displace air from the pulmonary veins, and adding volume from the venous reservoir. After closure of the atrium during a Valsalva maneuver, the dog was placed in a reverse Trendelenburg position and the aortic root and pulmonary vents were reopened. No intraoperative echocardiography was performed. Subsequently, with the dog in Trendelenburg position, the endoaortic balloon clamp was deflated under fluoroscopic guidance. External or internal defibrillation was performed if necessary. The dog was rewarmed to $37^{\circ} \mathrm{C}$, weaned from $\mathrm{CPB}$, and had all the cannulas removed. In the long-term (survival) group animals, a $22 \mathrm{~F}$ chest tube was placed in the left pleural cavity and connected to a Heimlich valve. Heparin was reversed with protamine $(1 \mathrm{mg} / 100 \mathrm{U}$ heparin).

The thermodilution catheter was reintroduced, volume replenishment was carried out to achieve a pulmonary artery occlusion pressure similar to preoperative values, and $\mathrm{CO}$ was measured. Left ventriculography was then performed.

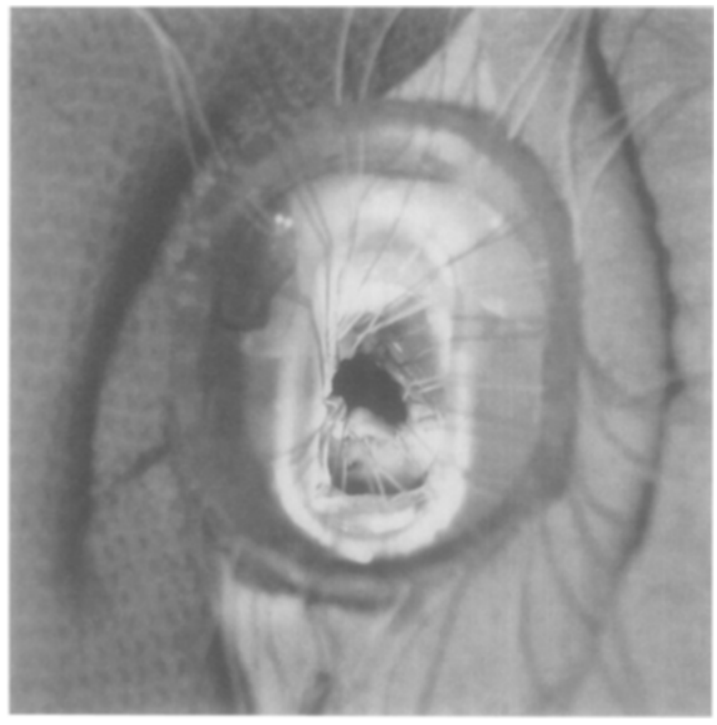

Fig. 6. Sutures passed through mitral valve anulus.

The acute study animals were sacrificed immediately after operation, whereas the long-term study animals were maintained on $30 \mathrm{mg} / \mathrm{kg}$ intramuscular cephalothin (Keflin) twice daily for 48 hours, followed by $35 \mathrm{mg} / \mathrm{kg}$ oral cephalexin twice daily for 7 days, and anticoagulated with $1 \mathrm{mg} / \mathrm{kg}$ subcutaneous heparin, oral warfarin, and approximately $80 \mathrm{mg}$ oral aspirin daily. Prothrombin times were measured daily for 1 week and then weekly for the duration of the study. Warfarin was adjusted to keep the prothrombin time at three times the baseline value. Before the animals were sacrificed, transthoracic echocardiography was performed.

After the animals were heparinized and humanely killed, the hearts were removed. The valves were explanted, rinsed in distilled water, soaked in $2 \%$ trypsin to remove any debris, and subsequently examined by light microscopy $(\times 25)$ to assess the presence of any damage. In addition, samples of myocardium, aorta, kidneys, liver, spleen, bowel, and hind limb muscles were taken for histologic examination.

Statistical analysis was performed with paired $t$ tests. A $p$ value less than 0.05 was considered significant.

\section{Results}

All 15 dogs survived the operation. In all 15 studies, excellent visualization of the mitral valve was obtained directly through the oval port and with video-assisted thoracoseopy.

Eleven of the 15 prostheses were St. Jude Medical valves, ranging from 19 to $23 \mathrm{~mm}$ in size, and four were $18 \mathrm{~mm}$ CarboMedics valves. All dogs were successfully maintained on CPB for $114 \pm 24$ minutes (mean \pm standard deviation). Aortic crossclamp time was $68 \pm 14$ minutes (mean \pm standard deviation). Kinetically assisted venous drainage re- 


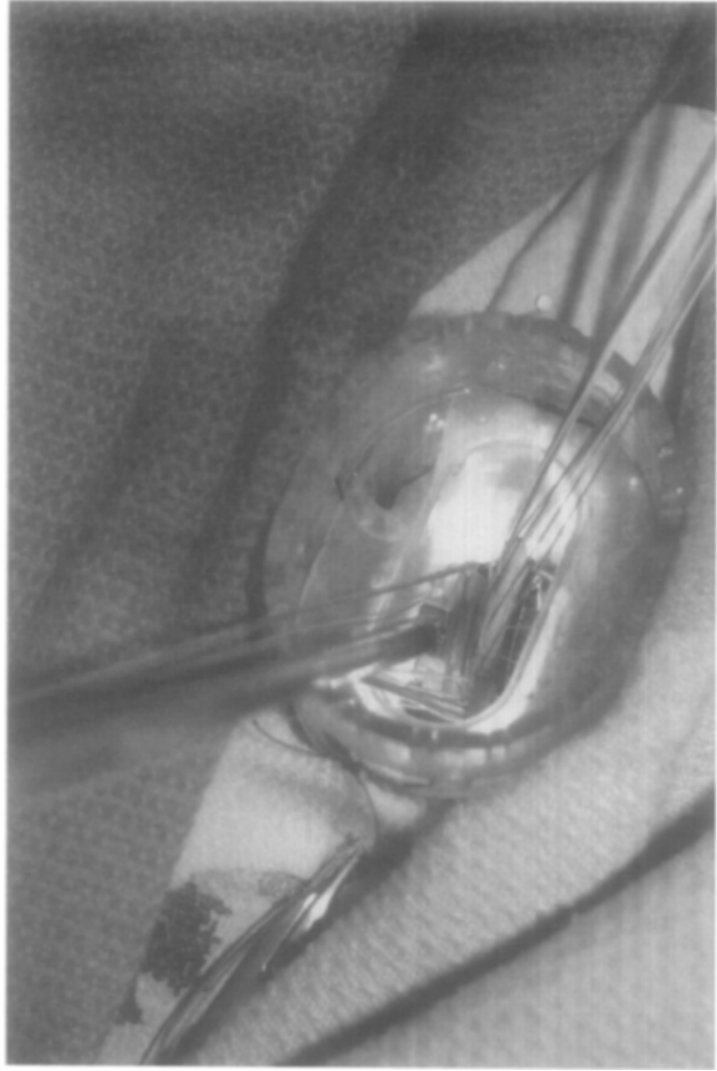

Fig. 7. Mechanical prosthesis being passed through oval port.

sulted in a venous line pressure of -40 to $-80 \mathrm{~mm}$ $\mathrm{Hg}$ during $\mathrm{CPB}$. Endopulmonary vent flows generally remained below $20 \mathrm{ml} / \mathrm{min}$ during this time, with satisfactory cardiac decompression.

The position of the endoaortic clamp was checked before deffation in three of the four long-term studies. No migration was observed. In one animal, the balloon of the endoaortic clamp deflated twice spontaneously and had to be replaced, without untoward effects. In all 15 animals, there was no clinical, radiographic, or postmortem evidence of aortic insufficiency or aortic valve damage.

At the completion of the surgical procedure, the endoaortic clamp was successfully deflated and the animals were resuscitated to sinus rhythm and weaned from CPB without inotropic support. Preoperative and postoperative $\mathrm{CO}$ measurements were obtained: the mean preoperative $\mathrm{CO}$ was $2.8 \pm$ $0.7 \mathrm{~L} / \mathrm{min}$, with pulmonary artery occlusion pressure of $7 \pm 4 \mathrm{~mm} \mathrm{Hg}$. The postoperative values were not significantly different at $2.6 \pm 0.6 \mathrm{~L} / \mathrm{min}$ and $9.0 \pm 4$ $\mathrm{mm} \mathrm{Hg}$, respectively.

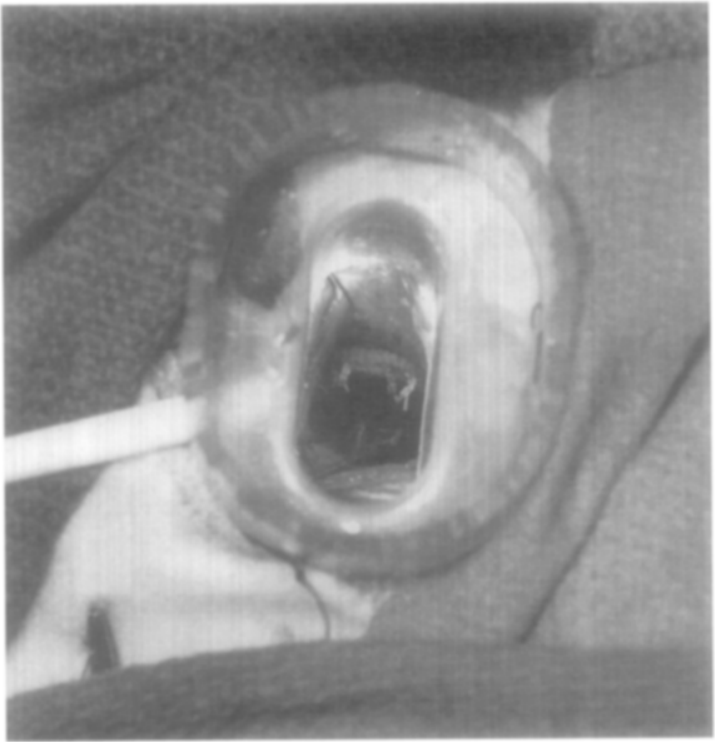

Fig. 8. Prosthesis sutured in place.

There was minimal entrapment of the anterior leaflet into the closing mechanism of the prosthesis in two of the early acute study animals. This produced mild to moderate regurgitation on left ventriculography.

Three of the four dogs in the survival study were anticoagulated uneventfully. One dog had upper gastrointestinal bleed necessitating transfusion. Four weeks after operation, before they were killed, all four dogs underwent transthoracic echocardiography. This revealed normal right and left ventricular function, no aortic regurgitation, and excellent function of the mitral prosthesis. Light microscopic examination $(25 \times)$ of the mitral prosthesis was also performed and revealed no evidence of damage. Postmortem examination of the heart demonstrated normal healing of the valve. Examined of other organs did not reveal any pathologic changes.

\section{Discussion}

The goal of this study was to evaluate the feasibility of replacing the mitral valve in a minimally invasive fashion. The application of these techniques to cardiac surgery has historically been hampered by the inability to provide adequate myocardial protection and cardiopulmonary support. ${ }^{7}$ The introduction of our novel method of endovascular myocardial protection allows the establishment of a quiet, bloodless surgical field, with the heart optimally protected and decompressed and with adequate systemic support provided by CPB. ${ }^{8}$ 
The preoperative and postoperative $\mathrm{CO}$ measurements in the presence of comparable preloading conditions demonstrate that excellent myocardial preservation can be accomplished with this method. A more detailed assessment of myocardial preservation achieved with the endovascular CPB system, as opposed to the standard open-chest system, was performed by Schwartz and colleagues. ${ }^{9}$ They found no significant differences. Furthermore, the endovascular CPB system was previously used in "portaccess coronary artery bypass grafting," achieving the same excellent results in terms of myocardial protection and preservation of end-organ function. ${ }^{10,11}$ In our study, the ability to adequately visualize the mitral valve was also tested. Superb exposure of the valve and its apparatus was accomplished by direct visualization through the oval port and by video-assisted thoracoscopy.

The insertion of the oval port did not require rib spreading or gross thoracotomy. This technique thus introduces the possibility of reduced chest discomfort during postoperative recovery. ${ }^{12}$ Despite the presence of a normally sized left atrium, it was possible to easily manipulate the anatomic structures of interest by means of specifically designed instruments, without any resultant damage to the mechanical prosthesis according to microscopic examination. Entrapment of valve tissue into the closing mechanism of the mechanical prosthesis was encountered in two of the first acute animal studies, but this was probably related to initial inexperience.

During the last decade, modern surgical treatment of mitral valve diseases has expanded rapidly into a wide array of reconstructive procedures and percutaneous interventions. ${ }^{13-16}$ Replacement of the mitral valve remains a well-established treatment modality, however, accompanied by very low morbidity and mortality. ${ }^{17}$ Several approaches have been used for its performance, including median sternotomy, right thoracotomy, and left thoracotomy. ${ }^{18}$

The recent development of video-assisted thoracoscopy has resulted in significant advances in the management of chest diseases, mainly as a result of the ability to visualize the anatomic structures of interest with excellent resolution and of the development of specifically designed instruments that allow surgical maneuvers to be performed from outside the chest cage. The field of cardiac surgery has not enjoyed similar progress, however, because of the inability to arrest and protect the heart while maintaining end-organ function. The endovascular support and cardioplegic system we report here allowed us to obtain optimal visualization of the mitral valve and its subvalvular apparatus and to perform a technically satisfactory and uneventful implantation of a mechanical prosthesis. Because of the excellent exposure, it is reasonable to infer that more complex resection, decalcification, and reconstruction of the mitral valve and its apparatus would be feasible.

There are several limitations to the model and the study design. The canine aorta is remarkably shorter than the human aorta, limiting the area available for inflation of the endovascular clamp. However, no injuries to valvular or vascular structures were created. Although the absence of atherosclerosis prevents us from fully assessing the possibility of aortic injury, it seems theoretically possible to decrease atheroembolization associated with aortic cannulation and external crossclamping. ${ }^{19}$

The anatomic configuration of the dog's chest was another significant limitation of our model. The heart is closer to the lateral chest wall in dogs than in human beings because the major axial diameter of the canine chest cage is the anteroposterior. This feature in turn allows an easier and closer approach to the mitral valve than would be possible in human beings. Also, the presence of a normal valve and apparatus without annular calcification significantly simplified the operation. Deairing of cardiac chambers performed according to standard maneuvers appeared to be adequate, as indicated by the absence of neurologic deficits in the four long-term study dogs. ${ }^{20,21}$ Finally, this was not a controlled, randomized study: our goal was to study the feasibility, safety, and efficacy of this new technology.

On the basis of these data, we conclude that it is possible to perform a replacement of the mitral valve with a mechanical prosthesis through small thoracic ports in an animal model. Applied to human beings, this minimally invasive approach has the potential to decrease postoperative discomfort, morbidity, and overall cost, and to expedite the return to gainful activity, while still providing the benefits of a well-established therapeutic modality. A clinical trial of this method is in progress.

REFERENCES

1. Begos DG, Modlin IM. Laparoscopic cholecystectomy: from gimmick to gold standard. J Clin Gastroenterol 1994;19:32530.

2. Mack MJ, Aronoff RJ, Acuff TE, et al. Present role of thoracoscopy in the diagnosis and management of diseases of the chest. Ann Thorac Surg 1992;54:403-9. 
3. Starr A, Edwards ML. Mitral replacement: clinical experience with a ball-valve prosthesis. Ann Surg 1961;54:726.

4. Baudet EM, Puel V, Mc Bride, et al. Long-term results of valve replacement with the St. Jude Medical prosthesis. J Thorac Cardiovasc Surg 1995;109:858-70.

5. Khan S, Chaux A, Matloft, et al. The St. Jude Medical valve: experience with 1000 cases. J Thorac Cardiovasc Surg 1994; 108:1010-20.

6. Navano K, Koyanagi H, Hashimoto A, et al. Twelve years' experience with the St. Jude Medical valve prosthesis. Ann Thorac Surg 1994;54:697-703.

7. Peters WS. Minimally invasive cardiac surgery by cardioscopy. Aust J Thorac Surg 1993;2:152-4.

8. Stevens JH, Siegel LC, Mitchell RS, et al. Closed-chest coronary artery bypass with cardioplegic arrest in the dog (abstract). Circulation 1994;90(4 Pt 2):251.

9. Schwartz DS, Ribakove GH, Grossi EA, et al. Minimally invasive cardiopulmonary bypass with cardioplegic arrest: a closed chest technique with equivalent myocardial protection. J Thorac Cardiovasc Surg 1996;111:556-66.

10. Stevens JH, Burdon TA, Peters WS, et al. Port-access coronary artery bypass grafting: a proposed surgical method. J Thorac Cardiovasc Surg 1996;111:567-73.

11. Stevens JH, Burdon TA, Siegel LC, et al. Port-access coronary artery bypass with cardioplegic arrest: acute and chronic studies. Ann Thorac Surg 1996;62:435-41.

12. Hazelrigg SR, Landrenau RJ, Boley TM, et al. The effect of muscle-sparing versus standard posterolateral thoracotomy on pulmonary function, muscle strength, and postoperative pain. J Thorac Cardiovasc Surg 1991;101:394-401.

13. Reyes VP, Soma Raju B, Wynne J, et al. Percutaneous balloon valvuloplasty compared with open surgical commissurotomy for mitral stenosis. N Engl J Med 1994;331:961-7.

14. Deloche A, Jebara VA, Relland JY, et al. Valve repair with Carpentier techniques: the second decade. J Thorac Cardiovasc Surg 1990;99:990-1002.

15. Akins CW, Hilgenberg AD, Buckley MJ, et al. Mitral valve reconstruction versus replacement for degenerative or ischemic mitral regurgitation. Ann Thorac Surg 1994;58:668-76.

16. Galloway AC, Colvin SB, Baumann FG, et al. Current concepts in mitral valve reconstruction for mitral insufficiency. Circulation 1988;78(Suppl 1):97-105.

17. Society of Thoracic Surgeons. Data analysis of the Society of Thoracic Surgeons National Cardiac Surgery Database: the third year-January 1994. Minneapolis (MN): Summit Medical Systems, 1994.

18. Tribble CG, Killinger WA Jr, Harman PK, Crosby IK, Nolan SP, Kron IL. Anterolaterolateral thoracotomy as an alternative to repeat median sternotomy for replacement of the mitral valve. Ann Thorac Surg 1987;43:380-2.

19. Marshall WG, Barzilai B, Kouchoukas NT. Intraoperative ultrasonic imaging of the ascending aorta. Ann Thorac Surg 1989;48:339-44.

20. Linden J, Casimir-Ahn H. When do cerebral emboli appear during open heart operation? A transcranial Doppler study. Ann Thorac Surg 1991;51:237-41.

21. Orihashi K, Matsuura Y, Hamanaka Y, et al. Retained intracardiac air in open heart operation examined by trans- esophageal echocardiography. Ann Thorac Surg 1993;55: 1467-71.

\section{Discussion}

Dr. Randall B. Griepp (New York, N.Y.). With respect to your conclusion that a clinical trial is appropriate, the mitral valve is a little further from the chest wall in people than it is in dogs. Clinically, what incision do you propose, and do you have any idea how you are going to get the mitral valve close enough to be reached?

Dr. Pompili. To surgically manipulate the mitral valve, we use specifically designed instruments. As far as the surgical approach in a human being is concerned-and there is actually a phase 1, FDA-approved clinical trial open at Stanford-we plan to approach the mitral valve from the right side of the chest through the fourth intercostal space with an incision that probably will be around 7 or $8 \mathrm{~cm}$ long, and we plan either to once again use the oval port or, if necessary, to resect a short segment of rib. The remaining steps of the operation would be substantially similar to what was shown in my presentation.

Dr. Peter Yong (Dallas, Tex.). I have just two questions for you. Can you share with us the technique of your deairing on the left side of the heart? In the animal model, when you place the animal in the lateral position, your access to the mitral valve is quite easy. In a human being, do you think that you can use the same technique and place sutures in a mitral valve replacement? The mitral valve is far away from the chest wall surface and less accessible. Could you share some of your insights with me?

Dr. Pompili. In response to the first question, deairing in the dog was a little more laborious than we suspect it will be in human beings. The dog was initially placed in a reverse Trendelenburg position, while the aortic root vent, which is provided through the same catheter as the balloon for inflation for the clamp, is working. Volume is then added from the pump and the anesthesiologist performs some Valsalva maneuvers; subsequently, once the clamp is deflated, the dog is placed in the Trendelenburg position and the same maneuvers are performed.

As for your second question, we are actually submitting these data to the American Heart Association meeting. We have already performed four mitral valve replacements in human beings in which the approach was from the right side. You are absolutely correct in your anatomic remarks. From the right side, the mitral valve anulus is certainly more distant from the chest wall; from the left side, according to some cadaver studies that we have conducted, the mitral anulus is actually closer to the chest wall. However, from this initial preliminary clinical experience, the distance between the chest wall and the anulus does not seem to be an overwhelming problem. Manipulation of the valve can be performed without difficulty with the specifically designed instruments. 